\title{
Evaluation of Microleakage in Endodontically Treated Teeth with Two Different Types of Sealers: Bioceramic Based Sealer and AH26; An in vitro Study
}

\author{
Ola M. Sakr ${ }^{1,2 *}$, Manal M. Abdelhafeez ${ }^{1,3}$, Salsabil M. AlKhalifah ${ }^{4}$ and \\ Sha'eah Mohammad AlWehaiby ${ }^{4}$ \\ ${ }^{1}$ Department of Conservative Dentistry, College of Dentistry, Qassim University, \\ Kingdom of Saudi Arabia \\ ${ }^{2}$ Department of Conservative Dentistry, College of Dentistry, Misr University for science and \\ Technology, Egypt \\ ${ }^{3}$ Department of Endodontics, Modern Science and Art University, Egypt \\ ${ }^{4}$ Collage of Dentistry, Qassim University, Kingdom of Saudi Arabia \\ *Corresponding author
}

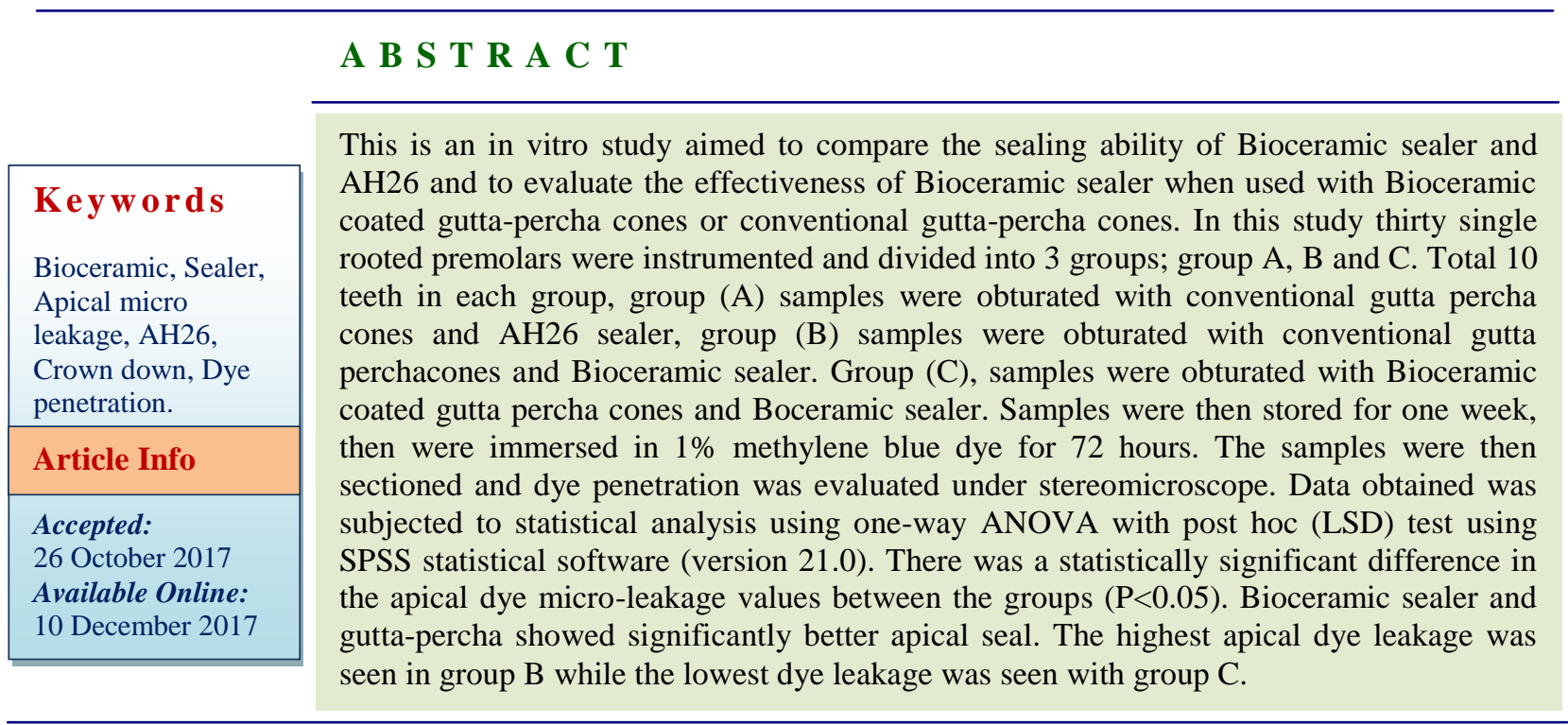

\section{Introduction}

The purpose of root canal treatment is to maintain a tooth free of infection. It's attributed to various essential factors such as thorough cleaning, disinfecting, proper instrumentation and obturation of the root canal system. According to the American association of endodontic AAE; in order to achieve successful treatment, the use of materials and techniques capable of providing a fluid tight seal from the apical part of the canal to the coronal margin in order to prevent reinfection. Ingle et al., (2008), they indicated that $58 \%$ of failed endodontic treatment due to incomplete obturation which 
means no obturation done or inadequate which is not seal the canal adequately. Sealers play a major role in achieving the fluid tight seal because gutta- percha alone does not provide bond with dentinal walls, in the past decades, various sealers and obturating materials have been used and tested to achieve the best properties and results with root canal treatment and hermetic seal.

Ideal root canal sealer properties as described by Grossman (1982):

It should make a hermetic seal.

It should be radiopaque to be visualized on $\mathrm{x}$ rays.

It should have fine particles.

It should not shrink.

It should not cause any discoloration to tooth structure.

It should be bacteriostatic.

It should has adequate setting time.

It should be insoluble in tissue fluids.

It should not cause any irritation of the periapical tissue.

It should be easily removed when needed i.e. soluble in common solvent.

A new sealer introduced nowadays to best achieve hermetic seal one of them is BC sealer (Endosequence bio ceramic sealer).

BC sealer as described by manufacturer is premixed injectable, insoluble, radiopaque and composed of calcium phosphate monobasic, calcium silicate, calcium hydroxide and zirconium oxide. Many studies done on Bioceramic based sealers and resin coated gutta percha showed a good biocompatibility and superior sealing capacity among different materials has been used.

There are two major advantages of BC sealer which are: it is biocompatible with tissues and it contains calcium phosphate which will improve the sealing to dentinal walls. On the other hand the biggest disadvantage is difficulty in retreatment or preparation of post-space Al-haddad et al., (2016). Study by Nazzalin (2011), compared two types of sealer with 2 different obturation techniques, they found that there was no significant difference between the techniques, but the difference was noticed in using roth sealer which shows lower bacterial leakage when compared with BC sealer.

Another study by Pawar in 2014, stated that although micro leakage must happen in root canal treated teeth which is attributed to various factors taking anatomical variation in consideration, but fortunately there was different results regarding sealing ability between different types of sealers. They found that newly introduced BC sealer showed better results in sealing ability when compared to AH plus sealer.

The use of sealer in root canal treatment is very important, it has capability of sealing the gaps that present between the dentin and filling material thus it will stop bacterial invasion and leakage in study by Dr. Al Thanzeer Usman et al., (1984) showed that the dye penetration was least in Endosequence $\mathrm{BC}$ sealer followed by $\mathrm{AH}$ Plus and EndoRez.

Polineni et al., in 2016 concluded that when comparing BC sealer with epoxy resin sealer and mineral trioxide aggregate higher leakage present at MTA sealer and low leakage was present at epoxy resin sealer, and they also found the coronal part is sealed better than the apical part. 
The purpose of this an in vitro study was to evaluate the apical sealing ability of BC sealer when used with two different types of GP and compare it with the AH26 sealer and conventional GP cones, which is used in our clinics.

\section{Hypothesis}

Null Hypothesis: There is no significant difference in microleakage between bioceramic sealer and $\mathrm{AH} 26$ sealer.

Alternative Hypothesis: There is significantly less microleakage with the bioceramic sealer compared with AH26 sealer.

\section{Materials and Methods}

In this an in vitro study, A total of 30 extracted mandibular permanent 2nd premolars with single straight canals were used.

The following were the exclusion criteria:

Teeth with root caries, restorations or immature apices.

Internallexternal resorption, fractured or cracked teeth.

Calcified lcurved canals more than 30 degrees according to Schneider's method.

And which was confirmed by radiographs

The samples were stored in $5.25 \%(\mathrm{NaOCl})$ solution in room temperature to prevent bacterial growth.

\section{Specimen preparation}

First, the samples were removed from $5.25 \%$ $\mathrm{NaOCl}$ solution and dried. Subsequently, they were mechanically cleaned with hand scaler to remove surface soft tissue and calculus then rinsed and stored in normal saline Access cavity was prepared with a round bur then deroofing with end Z-bur using a high speed hand piece under continuous water spray.

\section{Canal preparation and filling}

Working length (WL) was determined by inserting a K-file\#15 until its tip just shown at the apex, $1 \mathrm{~mm}$ short of this measurement is the determined WL. Radiographs taken for working length confirmation are given in Figure 1.

All the samples were prepared using a crown down technique with a protaper rotary system to F3 file (DENTSPLY MAILLEFER) taper $=.04$. Canals were irrigated between each file with EDTA $17 \%$ and freshly prepared $2.25 \%$ $\mathrm{NaOCl}$ alternatively, the final irrigation was done with normal saline. Then, all the canals were dried with sterile paper points.

After completion of the instrumentation, the teeth were randomly divided into 3 experimental groups $(n=10)$. The groups were labelled as group A, B and C.

Group (A); using AH26 sealer (DENTSPLY DETREY $\mathrm{GmbH}$ ) with conventional guttapercha (META BIOMED CO. LTD).

Group (B); using Bioceramic sealer (Brasseler USA, Savannah, GA), Endosequence, with conventional gutta-percha.

Group (C); using Bioceramic sealer with Bioceramic coated gutta-percha.

In all of the groups, root canal obturation was carried out using the crown down, single-cone obturation technique. A standardized guttapercha cone of the same size as the master file was placed into the root canal up to the working length and the tug back was verified. In group (A) and (B); an F3 protaper Gutta- 
percha cones were used. In group (C); size 30 BC coated gutta-percha were used. Guttapercha cones were coated with sealer and canals coated with sealers using lentulo spirals. Cone then inserted to the canal to the WL. Excess coronal gutta-percha was cut with a scissor then removed by heat carrier and condensed apically at the canal orifice. The samples then sealed coronally with glass ionomer cement (GIC). Each material was prepared and used according to the manufacturer's instructions.

Radiographs were taken for all the samples to assess the quality of the obturation (Figure 2). Then each group was stored in separate container for 1 week at $37^{\circ} \mathrm{C}$ and $100 \%$ humidity to insure complete setting of the sealer.

Later, external root surface of all the samples were dried and coated with2 layers of colored nail polish $2 \mathrm{~mm}$ short from the apex (Figure 3). The teeth were then immersed in $1 \%$ methylene blue dye solution for 3 days. Following this, the samples removed from the dye and rinsed under running tap water for 15 minutes.

\section{Samples preparation for micro leakage evaluation}

The samples were dried and the nail polish scrapped off with a scalpel. Teeth were then longitudinally sectioned in a buccolingual direction parallel to the long access of the tooth, markings were made 2 and $6 \mathrm{~mm}$ from the apex, the depth of dye penetration for each sample was measured under stereomicroscope X50 magnification, measurements were evaluated in units. Leakage was assessed from the most apical extent of gutta-percha to the most coronal point of dye penetration. Values for vertical dye penetration were then converted to millimeters.

\section{Statistical analysis}

For statistical analysis, one way ANOVA with Post hoc (LSD) test was used.

\section{Results and Discussion}

The results of this study showed that the highest vertical dye penetration was seen in group B (Figure 5) with mean $=1.9524$ followed by group A (Figure 4) with mean $=.2922$, while the least was observed in group $\mathrm{C}$ (Figure 6) with mean $=.0589$ (Table 1, 2, $3)$.

A high quality obturation is an important factor in successful endodontic treatment. We used to use Gutta perch semi-solid material to obturate the clean canal, but since it does not provide any bond with dentinal tubules we need to seal any gap present between them using sealers in order to prevent any leakage and reinfection. The purpose of the present study was to evaluate the sealing ability in apical part between two types of sealers; BC sealer and AH26 (resin-based sealer) using crown down technique.

In this study, microleakage was evaluated using dye penetration method. Methylene blue dye was employed due to its advantages of better penetration, simplicity and costeffectiveness.

Due to its low molecular weight, it penetrate and diffuse more deeply along root canal fillings, Stewart GG (1958) it remains the most used dye and it's been reported that methylene blue dye doesn't show any reaction with the hard tissues and showed accurate results in many previous studies.

The bond to canal walls is ultimate criteria to maintain the tight seal we look for in sealers, and to prevent bacterial re-invasion, as $\mathrm{AH} 26$ depends on micro-mechanical bond instead of 
chemical bond as $\mathrm{BC}$ sealer, by depending on its flow through dentinal tubules which will affect the goal of achieving apical good seal since apical third of the canal lacks density of dentinal tubules as proven in several studies.

The results shows the leakage was less in $\mathrm{BC}$ group, this goes with study by Pawar SS in (2014), stated that although micro leakage must happen in root canal treated teeth which is attributed to various factors taking anatomical variation in consideration, but fortunately there was different results regarding sealing ability between different types of sealers. They found that newly introduced $\mathrm{BC}$ sealer showed better results in sealing ability when compared to $\mathrm{AH}$ plus sealer. That could happen for many reasons, first of all antibacterial effects of BC sealer can play a very important factor in prevention of micro leakage.

Since its $\mathrm{pH}=12.8$ during the initial 24 hours of the setting process makes the bacterial growth very difficult.

Secondly flow rate; $\mathrm{BC}$ sealer has a fine particles which in turn will affect the flow rate, it has been variously reported as $23.1 \mathrm{~mm}$ and $26.96 \mathrm{~mm}$ in Al-haddad et al., (2016).

Table.1 comparison of three groups with respect to vertical penetration of dye by one way ANOVA

\begin{tabular}{|c|c|c|c|c|c|}
\hline \multicolumn{7}{|c|}{ ANOVA Micro-leakage } \\
\hline & Sum of Squares & df & Mean Square & F & Sig. \\
\hline Between groups & 21.320 & 2 & 10.660 & 3.439 & .047 \\
Within groups & 83.689 & 27 & 3.100 & & \\
Total & 105.009 & 29 & & & \\
\hline
\end{tabular}

Table.2 Shows a significant difference between group A and C

\begin{tabular}{|c|c|c|c|c|c|c|}
\hline \multicolumn{7}{|c|}{ LSD } \\
\hline \multirow{2}{*}{1} & 2 & $-1.66017 *$ & .78735 & .044 & -3.2757 & -.0447 \\
\cline { 2 - 7 } & 3 & .23337 & .78735 & .769 & -1.3821 & 1.8489 \\
\hline \multirow{2}{*}{3} & 1 & $1.66017 *$ & .78735 & .044 & .0447 & 3.2757 \\
\cline { 2 - 7 } & 3 & $1.98354 *$ & .78735 & .023 & .2780 & 3.5090 \\
\hline & 1 & -.23337 & .78735 & .769 & -1.8489 & 1.3821 \\
\cline { 2 - 7 } & 2 & $-1.89354 *$ & .78735 & .023 & -3.5090 & -.2780 \\
\hline
\end{tabular}

Table.3 Shows a mean of descriptive microleakage of each group

\begin{tabular}{|c|c|c|c|c|c|c|c|c|}
\hline \multicolumn{9}{|c|}{ Descriptive Micro-leakage } \\
\hline & \multirow{3}{*}{$\begin{array}{l}\mathrm{N} \\
10\end{array}$} & \multirow{3}{*}{$\begin{array}{l}\text { Mean } \\
.2922\end{array}$} & \multirow{2}{*}{$\begin{array}{c}\text { Std. } \\
\text { Deviation }\end{array}$} & \multirow[t]{2}{*}{ Std.Error } & \multicolumn{2}{|c|}{$\begin{array}{l}\text { 95\% Confidence Interval for } \\
\text { Mean }\end{array}$} & \multirow[t]{2}{*}{ Minimum } & \multirow[t]{2}{*}{ Maximum } \\
\hline & & & & & Lower Bound & Upper Bound & & \\
\hline 1 & & & .38337 & .12123 & .0180 & .5665 & .00 & .89 \\
\hline 2 & 10 & 1.9524 & 3.02345 & .95610 & -.2105 & .4 .1152 & .00 & 9.64 \\
\hline 3 & 10 & .0589 & 10249 & .03241 & -.0145 & .1322 & .00 & .24 \\
\hline Total & 30 & .7678 & 1.90289 & .34742 & .0573 & 1.4784 & .00 & 9.64 \\
\hline
\end{tabular}


Int.J.Curr.Microbiol.App.Sci (2017) 6(12): 3556-3564
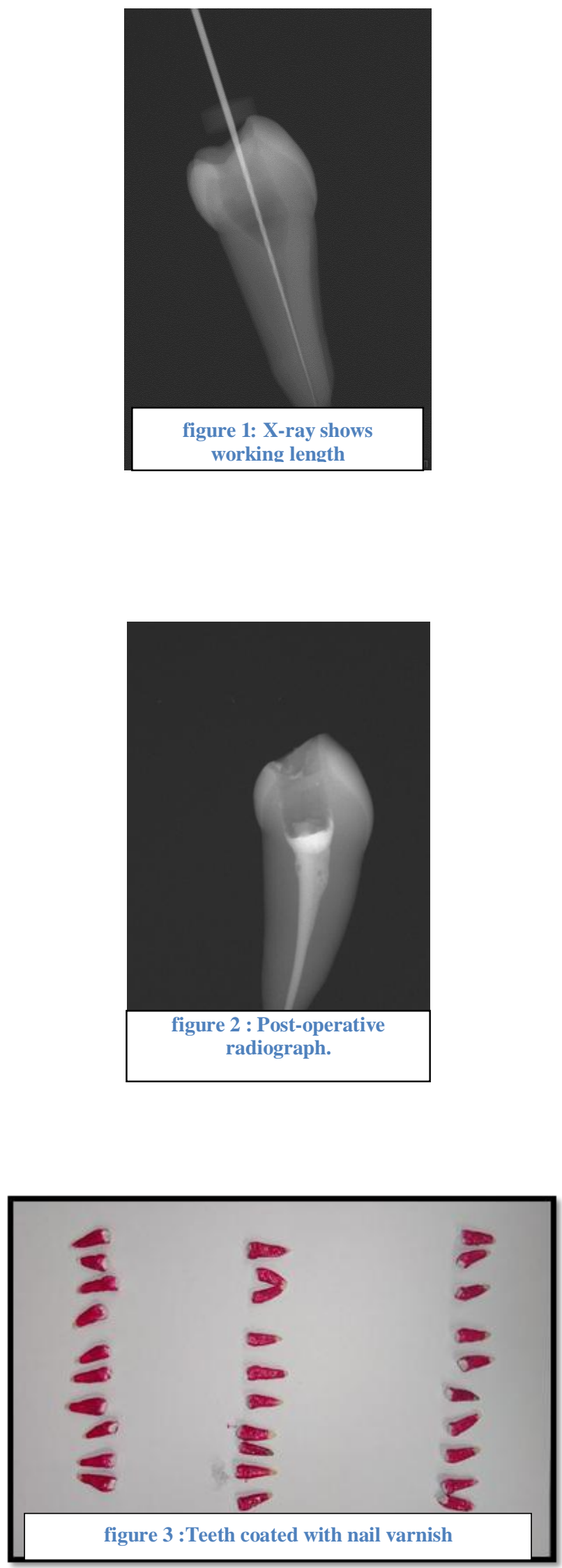


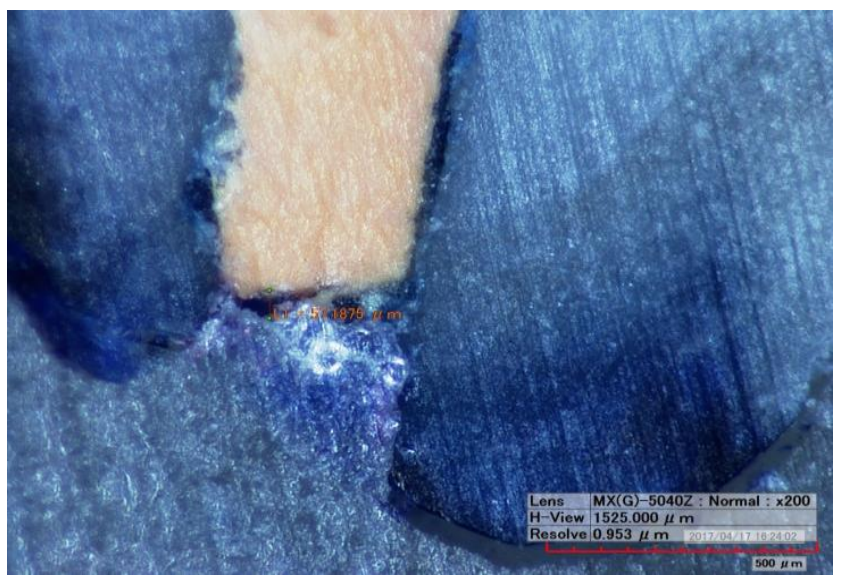

figure 4 : sample represent group $\mathbf{A}$.

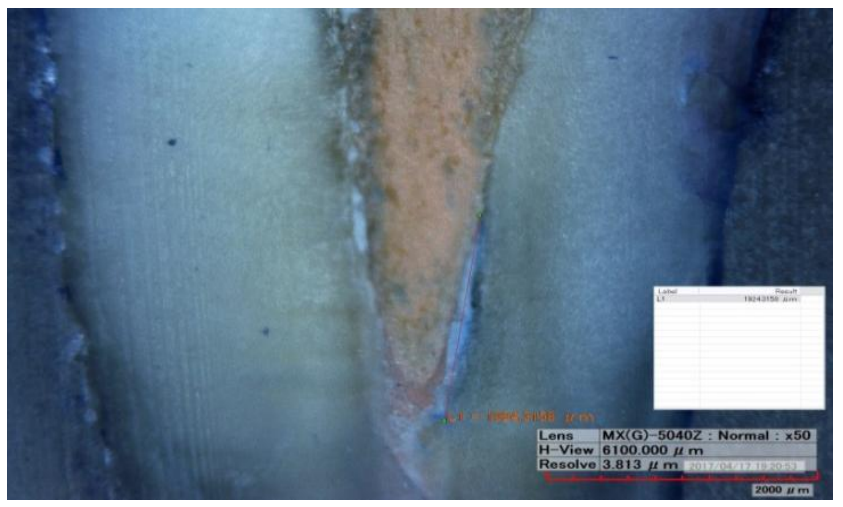

figure 5 : sample represent group $\mathbf{B}$.

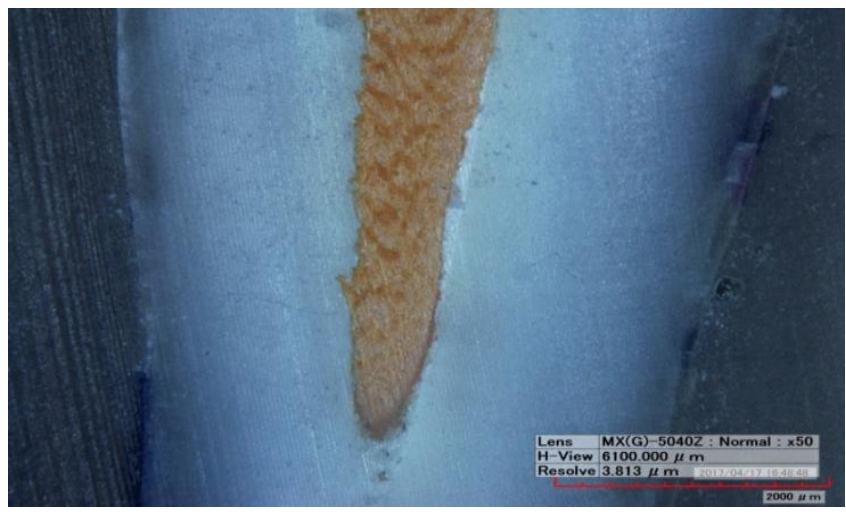

figure 6 : sample represent group $C$.

The BC sealer is non-resorbable, and since it's stable it maintains the seal achieved. AH26 (epoxy resin sealer) in the other hand is not stable, excellent seal and flow through accessory canals is achieved after root canal treatment but with the patient follow up, it will shrink and resorb with time leaves a gap which allows for bacterial reinvasion as proved by Miletić I et al.,(2002). 
Another study agrees with our results by $\mathrm{Al}$ Thanzeer et al., (1984) showed that the dye penetration was least in Endosequence sealer followed by $\mathrm{AH}$ Plus and EndoRez. Leakage was less in BC group, since it is consider insoluble and does not show any shrinkage upon setting which means that, there will be ultimate contact (bond) between core and dentinal tubules with no gaps that may lead to leakage and re-infection. Adding to this; BC sealer is hydrophilic material which require moisture environment to set, and upon setting it shows mild expansion, this expansion can reach up to $0.2 \%$ on completion of setting reaction this property is good for making a good seal, Koch et al., (2010).

A study by Sevimay et al., (2005) on resin sealers showed poorer marginal adaptation and penetration of resin sealers specially in the apical region of the canals. This difference may be due to the inability of apical efficient irrigation and removal of smear layer from the apical third of the canal since resin based sealers bond micro mechanically into dentinal tubules.

And this has been concluded in several studies that the dentinal density may affect sealer adaptation and penetration to canal walls.

AH26 showed least adaptation to dentinal wall according to punish et al., (2011) and it may be attributed to number, size and structure of dentinal tubules which resin sealer are dependent on for bonding and marginal adaptation.

McMichael in (2016) concluded that, Due to its low molecular weight, it penetrate and diffuse more deeply along root canal fillings.

Flow is an important subject that allows the sealer to fill difficult-to-reach areas, such as the isthmus, narrow irregularities and accessory canals.

One of the most important factor that may affect the sealing ability is irrigation solution, study by
Al-Zaka et al., (2013) found significant difference between Chlorhexidine (CHX) and Ethylene diaminetetra acetic acid (EDTA) with noticeable improvement in the first one. Since EDTA decrease the wetting ability of dentinal walls which in turn prohibit adhesion of material hydrophilic in nature i.e. BC sealer.

Resin based sealers are strongly dependent on smear layer removal for penetration. efficient irrigation is essential for effectiveness of resin based sealers as reported by several studies that incomplete removal of smear layer has obstructed the sealer from penetration the dentinal tubules.

A study done by Economides et al., (1999) concluded that presence of smear layer showed high apical microleakage in canals filled with AH26.

Use of Bioceramic sealer and Bioceramic coated gutta-percha group (C) resulted in less apical dye microleakage compared with group (A) and (B). It's been proven in multiple studies that Bioceramic sealer has better penetration and marginal adaptation to dentinal walls. Thus, concluding that the bioceramic sealer can be considered superior to $\mathrm{AH} 26$ due to its better sealing ability.

\section{References}

Al Thanzeer U, Shetty V, D'costa V. A stereomicroscopic study comparing the apical sealing ability of different root canal sealers; ceramic based sealer, methacrylate resin based sealer and epoxy resin based sealer- an in vitro study. $\mathrm{J}$ Endodon. 1984; 10: 558-62.

Al-haddad A, et al., Bioceramic-based root canal sealers: A review. International Journal of Biomaterials. 2016; 2016.

Al-zaka I. The Effect of Different Root Canal Irrigants on the Sealing Ability of Bioceramic Sealer. MDJ 2013; 10(1).

CobankaraFK, Adanir N, Belli S. Evaluation of the Influence of Smear Layer on the Apical and Coronal Sealing Ability of 
Two Sealers. Journal of Endodontics 2004; 30(6): 406-9

Economides N, Liolios E, Kolokuris I, Beltes P. Long-term evaluation of the influence of smear layer removal on the sealing ability of different sealers. J Endodon, 1999; 25: 123-5.

Gharib SR, Tordik PA, Imamura GM, Baginski TA, Goodell GG. A confocal laser scanning microscope investigation of the Epiphany obturation system. J Endod. 2007; 33: 957-61.

Grossman, L. "Obturation of root canal," in Endodontic Practice, L. Grossman, Ed., p. 297, Lea and Febiger, Philadelphia, $\mathrm{Pa}$, USA, $10^{\text {th }}$ edn, 1982.

Ingle JI, Bakland LK, Baumgartner JC. Ingle's Endodontics $6^{\text {th }}$ edn. Hamilton: BC Decker Inc; 2008; p. 1053-87.

Koch KA, Brave GD, Nasseh AA. Bioceramic Technology: Closing the endorestorative circle, Part 2. Dent Today. 2010; 29; 98.

Kokkas AB, Boutsioukis ACh, Vassiliadis LP, Stavrianos CK. Influence of the smear layer on dentinal tubule penetration depth by three different root canal sealers An in vitro study. J Endod. 2004; 30: 100-2.

Limkangwalmongkol S, Abbott PV, Sandler AB. Apical dye penetration with four root canal sealers and gutta-percha using longitudinal sectioning. J Endod., 1992; 18: 535-9.

Matloff IR, Jensen JR, Singer L, Tabibi A. A comparison of methods used in root canal sealability studies. Oral Surg Oral Med Oral Pathol., 1982; 53: 203-8.

McMichael, G.E., Primus, C.M., Opperman, L.A. Dentinal tubule penetration of tricalcium silicate sealers. J Endod. 2016;
42: 632-636.

Miletić I, Ribarić SP, Karlović Z, Jukić S, Bosnjak A, Anić I. Apicalleakage of five root canal sealers after one year of storage. J Endod. 2002; 28: 431-2.

Nazzal JF. An in-vitro comparison of bacterial microleakage of zinc-oxide eugenol and brasseler bioceramic sealer. J Endod 2011; 21(3).

Pawar SS, Pujar MA, Makandar SD. Evaluation of the apical sealing ability of bioceramic sealer, AH plus and epiphany: An in vitro study. J Conserv Dent. 2014; 17(6).

PG punish, K Shashukala. evaluation of the adaptation of resin based sealers epiphany, ah plus and ah26 to the root canal dentin by scanning electron microscope. Indian J Stomatol 2011; 2(4): 207-11.

Polineni S, Bolla N, Mandava P. Marginal adaptation of newer root canal sealers to dentin: A SEM study. J Conserv Dent. 2016; 19(4).

Sevimay S, Kalayci A. Evaluation of apical sealing ability and adaptation to dentine of two resin-based sealers. J Oral Rehabil. 2005; 32: 105-10

Starkey DL, Anderson RW, Pashley DH. An evaluation of the effects of methylene blue dye $\mathrm{pH}$ on apical leakage. J Endod 1993; 19: 435-439.

Stewart GG. A comparative study of three root canal sealing agents. J Oral Surg., 1958; 11: 1174-8.

White RR, Goldman M, Lin PS. The influence of the smeared layer upon dentinal tubule penetration by plastic filling materials. $\mathbf{J}$ Endodon. 1984; 10:558-62

\section{How to cite this article:}

Ola M. Sakr, Manal M. Abdelhafeez, Salsabil M. AlKhalifah and Sha'eah Mohammad AlWehaiby. 2017. Evaluation of Microleakage in Endodontically Treated Teeth with Two Different Types of Sealers: Bioceramic Based Sealer and AH26; An in vitro Study. Int.J.Curr.Microbiol.App.Sci. 6(12): 3556-3564. doi: https://doi.org/10.20546/ijcmas.2017.612.413 